\title{
Cucurbita maxima Pumpkin Seed Oil: from the Chemical Properties to the Different Extracting Techniques
}

\author{
Leila REZIG ${ }^{1 *}$, Moncef CHOUAIBI $^{1}$, Rosa Maria OJEDA-AMADOR ${ }^{2}$, \\ Sergio GOMEZ-ALONSO², Maria Desamparados SALVADOR², \\ Giuseppe FREGAPANE², Salem HAMDI ${ }^{1}$
}

\author{
${ }^{1}$ High Institute of Food Industries, Food Conservation and Valorization Laboratory, 58 Alain Savary Street, El Khadra City, 1003 Tunis, \\ Tunisia;_rezig@yahoo.fr(*correspondingauthor); moncef.chouaibi@yahoo.com.au; hamdisalemaziz@yahoo.com \\ ${ }^{2}$ Universidad de Castilla-La Mancha, Facultad de Ciencias Quimicas, Departamento de Quimica Analitica y Tecnologia de Alimentos, 13071 \\ Ciudad Real, Spain;RosaMaria.Ojeda@alu.uclm.es;Sergio.Gomez@uclm.es;Amparo.Salvador@uclm.es; Giuseppe.Fregapane@uclm.es
}

\begin{abstract}
Pumpkin seed oils are rich in bioactive compounds such as tocopherols, sterols, $\beta$-carotene, and lutein that have, along with some fatty acids, high nutritional value factors. In addition, it has so far been proven that these compounds have a positive effect on human health. The present study mainly aimed at evaluating the chemical composition and the bioactive compounds of pumpkin (Cucurbita maxima) seed oil of the 'Béjaoui' Tunisian cultivar using both cold pressing and solvent extraction methods. The seed oils contained substantial amounts of unsaturated fatty acids, particularly oleic and linoleic acids, with values ranging respectively from $28.19 \%$ for cold pressed pumpkin seed oil to $30.56 \%$ for pumpkin seed oil extracted by pentane and from $43.86 \%$ for pumpkin seed oil extracted by pentane to $46.67 \%$ for cold pressed pumpkin seed oil of the total amount of fatty acids. Investigations of different seed oils revealed that extraction techniques had significant effects on the antioxidant activity and the $\gamma$-tocopherol. Cold pressed pumpkin seed oil revealed the highest $\gamma$-tocopherol content (599.33 $\left.\mathrm{mg} \mathrm{kg}^{-1}\right)$ and the highest oxidative stability $(3.84 \mathrm{~h})$. However, the chloroform/methanol extracted pumpkin seed oil, which is rich in total phenolics $\left(54.41 \mathrm{mg}\right.$ Gallic Acid Equivalent $\mathrm{kg}^{-1}$ ), was a more effective scavenger of DPPH radicals $(250 \mu$ moles Trolox $\left.\mathrm{kg}^{-1}\right)$ than the poor phenolic pumpkin seed oils extracted by hexane and pentane $\left(110 \mu\right.$ moles Trolox $\mathrm{kg}^{-1} \mathrm{vs} 100 \mu$ moles Trolox $\mathrm{kg}^{-1}$ ). Based on its unique seed oil features, cold press extracted pumpkin seed may add great value to product innovation in the industrial, nutritional, cosmetic, and pharmaceutical fields.
\end{abstract}

Keywords: chemical analysis; extracting techniques; phytochemicals; pumpkin seeds; quality parameters

Abbreviations: MUFA: Monounsaturated Fatty Acids; PSO: Pumpkin seed Oil; PSOCM: Pumpkin Seed Oil chloroform/methanol extraction; PSOH: Pumpkin Seed Oil Hexane extraction; PSOP: Pumpkin Seed Oil Pentane extraction; PSO1: Pumpkin Seed Oil obtained by Komet DD 85 G Press; PUFA: Polyunsaturated Fatty Acids; SFA: Saturated Fatty Acids.

\section{Introduction}

Pumpkin seeds are a rich source of bioactive compounds such as $\omega-3,-6$ and -9 fatty acids, $\alpha$ - and $\gamma$ - tocopherols, sterols, $\beta$-carotene and lutein (Murković et al., 2004; Nederal Nakić et al., 2006; Salgin and Korkmaz, 2011; Rezig et al., 2012; Jiao et al., 2014). Pumpkin seeds have frequently been used for edible and medicinal purposes. Similarly, pumpkin seed oil has recently gained much attention not only as edible oil, but also as a potential nutraceutical. It is dichromatic, viscous oil that has been documented for its strong antioxidant activity (Stevenson $e t$ al., 2007). Moreover, the most remarkable health benefits of pumpkin seed oil are prostate disease prevention, retardation of hypertension progression, reduction of bladder and urethral pressure, urinary disorders prevention, and the alleviation of diabetes by promoting hypoglycaemic activity (Nishimura et al., 2014). Such health benefits require effective extraction techniques in order to guarantee a high-quality pumpkin seed oil (PSO). 
664

It is known that organic solvents are frequently used to extract oil from the seeds. $n$-Hexane is a typical solvent that is commercially used in oil extraction from different plant materials. However, its usage is now under close examination due to growing governmental control and concerns about consumer safety, especially regarding organic solvents' use in food-processing industries. Consequently, environmental rules and regulations plus an increasing awareness of health risks pushed manufacturers to adopt novel alternatives in the use of organic solvents for oil extraction (Mitra et al., 2009).

In this regard, several researches have already been conducted with the sole aim of developing new extraction methods as viable alternatives to organic solvents for the sake of meeting the growing consumer demand for more natural products. Such alternatives include supercritical $\mathrm{CO}_{2}$ extraction (Mitra et al., 2009), aqueous enzymatic extraction (Qi, 2012), microwave-assisted aqueous enzymatic extraction (Jiao et al., 2014), or cold pressing extraction (Nederal Nakić et al., 2014; Rabrenović et al., 2014). These extraction techniques were subsequently applied to pumpkin seeds obtained from different varieties and originating from different geographical areas all over the world.

To the best of our knowledge, no research about the chemical properties of PSO obtained by different solvent polarities and different extracting methods has been previously carried out, particularly for the North African varieties. For that reason, this study explored the pumpkin seed oil extraction of the 'Béjaoui' Tunisian cultivar using both cold pressing and solvent extraction methods with different polarities. Eventually, the chemical properties, fatty acid composition and antioxidant activities were first evaluated and then compared with those extracted with cold pressed PSO and organic solvents.

\section{Materials and Methods}

All reagents used in the assessment procedure were of analytical grade or HPLC grade and were supplied by Merck (Darmstadt, Germany).

\section{Seed material}

Pumpkin seeds (Cucurbita maxima) were brought from a local market in the town of Chebika $\left(35^{\circ} 37^{\prime} 7.15^{\prime \prime} \mathrm{N}\right.$, $9^{\circ} 55^{\prime} 33.52^{\prime \prime} \mathrm{E}$ ) in the governorate of Kairouan, Tunisia. The seeds were directly isolated, washed to remove impurities, and then air-dried.

\section{Oilextraction}

Oil extraction by solvent

Prior to analysis, a heavy-duty grinder (Brown, Germany) was used to grind whole seeds into a fine powder, which was obtained with the help of a 200 mesh stainless steel filter. The powder was then stored at $4^{\circ} \mathrm{C}$ for further use. The seed flour was subsequently defatted with three solvents, namely pentane, hexane, and a mixture of chloroform/methanol $(3: 1, \mathrm{v} / \mathrm{v})$. The flour/solvent slurry, of which ratio was $1: 10 \mathrm{w} / \mathrm{v}$, was stirred for $24 \mathrm{~h}$. The mixture was then centrifuged for $15 \mathrm{~min}\left(\right.$ at $\left.4^{\circ} \mathrm{C}\right)$ and the supernatant was filtered through a $0.45 \mu \mathrm{m}$ Whatman filter paper. The extraction procedure was repeated three times and the solvent was removed using a rotary evaporator at $40{ }^{\circ} \mathrm{C}$. The seed oil was drained under a nitrogen atmosphere and was then stored in a freezer at $-20^{\circ} \mathrm{C}$ for further examination. The Pumpkin seed oils extracted by pentane, hexane, and chloroform/methanol would be respectively called PSOP, PSOH, and PSOCM.

\section{Oil extraction by cold pressing}

Cold pressing is carried out three times by directly pressing raw/dried seeds on a continuous screw press at a low temperature. Note that in the present examination the pumpkin seed oil was mechanically obtained using a Komet DD $85 \mathrm{G}$ screw press, named as PSO1 (IBG Monforts Oekotec GmbH \& Co. KG, Mönchengladbach, Germany). Due to the fact that the cold pressing oil technology excludes any thermal processing of material during the preparation phase, this may cause some complexities in the initial stage of using a screw press. In order to avoid risk and achieve greater efficiency, the head of the screw press is heated to a temperature ranging from 60 to $70{ }^{\circ} \mathrm{C}$ before starting the pressing procedure. For that purpose, a specially designed heating ring, connected to an automatic temperature control device, was attached to the head of the screw press. Head pre-heating does not obviously affect the temperature of the extracted oil because the heaters are always turned off when optimal seeds flow has already been achieved (Martinez et al., 2013).

The extracted oil was later separated from the sediment by centrifugation at $5000 \mathrm{rpm}$ (Hettich Zentrifugen, model Universal 32R) for $10 \mathrm{~min}$ at $24^{\circ} \mathrm{C}$ and stored in a freezer at $-20^{\circ} \mathrm{C}$.

\section{Fatty acid composition}

Fatty acids were determined by the analytical methods described in the European Parliament and the European Council in EEC regulation 2568/91(European Economic Community, 1991). The fatty acids were converted to fatty acid methyl esters (FAMEs) before being analyzed. This is done through shaking off a solution of $0.2 \mathrm{~g}$ of oil and $3 \mathrm{ml}$ of hexane with $0.4 \mathrm{ml}$ of $2 \mathrm{~N}$ methanolic potassium hydroxide. The FAMEs were then analyzed in a HewlettPackard model 4890D Gas Chromatograph furnished with an HP-INNOWax fused silica capillary columns (CrossLinked PEG), $30 \mathrm{~m} \times 0.25 \mathrm{~mm} \times 0.25 \mathrm{~m}$, and a flame ionization detector (FID). Inlet and detector temperatures were held at $230^{\circ} \mathrm{C}$ and $250^{\circ} \mathrm{C}$, respectively. The initial oven temperature was held at $120^{\circ} \mathrm{C}$ for $1 \mathrm{~min}$ and then it was raised to $240{ }^{\circ} \mathrm{C}$ at a rate of $4.0^{\circ} \mathrm{C} \mathrm{min}^{-1}$ for $4 \mathrm{~min}$. The FAMEs injected volume was $1 \mu \mathrm{l}$ and nitrogen was used as the carrier gas at $1 \mathrm{ml} \mathrm{min}^{-1}$ with a split inlet flow system at a 1:100 split ratio. Then, heptadecanoic acid C17:0 was added as an internal standard before methylation so as to measure the amount of fatty acids. Eventually, the fatty acid contents were measured using a 4890A Hewlett-Packard integrator. The FAMEs peaks were identified by comparison with the retention times of a standard mixture. The peak areas were computed, and the percentages of the FAME were obtained as area percentages by direct normalization. 


\section{Tocopherols}

Tocopherols were identified according to the American Oil Chemist's Society (AOCS) Method Ce 8-89 (AOCS, 1989). An n-hexane oil solution was closely examined by using High Performance Liquid Chromatography HPLC (HP series 1100) and a desiccant in the form of a silica gel (Lichrosorb Si-60 column)with a particle size of $5 \mu \mathrm{m}, 250$ $\times 4.6$ i.d.; Sugerlabor, Madrid, Spain. The solution was eluted, in due course, with n-hexane/ 2-propanol (98.5: 1.5, $\mathrm{v} / \mathrm{v}$ ) at a flow rate of $1 \mathrm{ml} \mathrm{min}^{-1}$. A Waters 470 fluorescence detector was eventually utilized with excitation and emission wave lengths adjusted to 292 and $330 \mathrm{~nm}$ respectively.

\section{Determination of total phenolic content (TPC)}

Phenolic compounds were isolated by a 2-time extraction of a solution of oil in hexane $(5 \mathrm{~g}$ of oil into $10 \mathrm{ml}$ of hexane) with $10 \mathrm{ml}$ of methanol/water mixture (80:20, v/v). $500 \mu \mathrm{l}$ of the Folin - Ciocalteau reagent (Merck Schuchardt OHG, Hohenbrunn, Germany) was added to a suitable aliquot of the combined extracts, and in $3 \mathrm{~min}$, a 1 $\mathrm{ml}$ of saturated sodium carbonate solution $(35 \%, \mathrm{w} / \mathrm{v})$ was further added to the reaction mixture. The solution was then reduced to a $10 \mathrm{ml}$ water dilute and in $1 \mathrm{~h}$ the absorbance set at $725 \mathrm{~nm}$ was calculated, against a blank solution, with a UV-visible spectrophotometer. The values were either calculated as mg gallic acid equivalents (GAE) per a kilogram of oil (Vázquez-Roncero et al., 1973; Gutfinger, 1981).

Analysis of phenolic compounds by HPLC-DAD-MS

Individual phenolic compounds were determined by an HPLC-DAD-ESI-MS/MS method adapted from conditions previously described (Castillo-Muñoz et al., 2009). The analysis was carried out by using an Agilent 1100 series system (Agilent, Waldbronn, Germany) equipped with a photodiode array detector (DAD) and an LC/MSD Trap VL electrospray ionization mass spectrometry (ESI-MS/MS), which were both coupled with an Agilent ChemStation used for data processing.

Aliquots $(1.75 \mathrm{ml})$ of phenolic extracts were evaporated in a rotary evaporator at $35^{\circ} \mathrm{C}$ under vacuum, and were eventually dissolved in $200 \mu \mathrm{l}$ of methanol/water (20:80, $\mathrm{v} / \mathrm{v}$ ) by being sonicated $(5 \mathrm{~min})$ and vortexed $(2 \mathrm{~min})$ before injecting $20 \mu \mathrm{l}$ in the system. Separation was achieved on a narrow-bore column Zorbax Eclipse XDB-C18 (2.1 x 150 $\mathrm{mm}$; $3.5 \mu \mathrm{m}$ particle; Agilent), with pre-column Zorbax Eclipse XDB-C8 (2.1 x $12.5 \mathrm{~mm}$; 5 m particle; Agilent), both thermostated at $40{ }^{\circ} \mathrm{C}$ by using a ternary gradient and

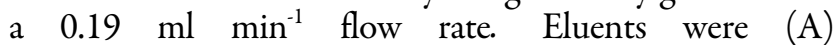
acetonitrile/water/formic acid (3:88.5:8.5 v/v/v), (B) acetonitrile/water/formic acid (50:41.5:8.5 v/v/v), and (C) methanol/water/formic acid (90:1.5:8.5 v/v/v). The linear solvents' gradient was as follows: zero $\mathrm{min}, 98 \% \mathrm{~A}, 2 \% \mathrm{~B}$, and $0 \% \mathrm{C} ; 8 \mathrm{~min}, 98 \% \mathrm{~A}, 2 \% \mathrm{~B}$, and $0 \% \mathrm{C}$; $40 \mathrm{~min}, 70 \%$ A, $17 \% \mathrm{~B}$, and $13 \% \mathrm{C}$; $54 \mathrm{~min}, 50 \% \mathrm{~A}, 30 \% \mathrm{~B}$, and $20 \% \mathrm{C}$; $54.5 \mathrm{~min}, 30 \% \mathrm{~A}, 40 \% \mathrm{~B}$, and $30 \% \mathrm{C}$; $59 \mathrm{~min}, 0 \% \mathrm{~A}, 50 \%$ $\mathrm{B}$, and $50 \% \mathrm{C}$; $60 \mathrm{~min}, 0 \% \mathrm{~A}, 50 \% \mathrm{~B}$, and $50 \% \mathrm{C}$; and 67 min, $98 \%$ A, 2\% B, and 0\% C. An Ion Trap ESI-MS/MS detector was used in negative ion modes for the identification process. The parameters were set as follows:
The flow rate of nitrogen as dry gas at $8 \mathrm{~L} \mathrm{~min}^{-1}$; the drying temperature at $325^{\circ} \mathrm{C}$; the nitrogen nebulizer at $50 \mathrm{psi}$ and the scan range at $50-1,200 \mathrm{~m} / z$. The identification was particularly reached on the basis of spectroscopic data (UVVis and MS/MS), which were mainly obtained from authentic standards or previously stated data. The measurement was achieved by using the DAD chromatograms set at $280 \mathrm{~nm}$ and the calibration graph of a 4-hydroxybenzoic acid standard $\left(\mathrm{R}^{2}>0.999\right)$. All compounds were later indicated as mg per kg of phydroxybenzoic acid.

\section{Determination of carotenoids}

Carotenoid compounds $\left(\mathrm{mg} \mathrm{kg}^{-1}\right)$ were determined at $670 \mathrm{~nm}$ in cyclohexane using specific extinction values (Mínguez-Mosquera et al., 1991).

\section{Radical scavenging effect (DPPH)}

DPPH was used as a stable radical (Brand Williams et al., 1995). Several concentrations of phenolic extracts were first dissolved in methanol $(0.1 \mathrm{ml})$ and then added to a DPPH methanolic solution $\left(2.9 \mathrm{ml}, 6 \times 10^{-5} \mathrm{M}\right)$. The diminution in the absorbance of the resulting solution was then measured at $515 \mathrm{~nm}$ at $0 \mathrm{~min}$ and at $30 \mathrm{~min}$ with a Perkin-Elmer Lambda-Bio spectrometer (Beaconsfield, $\mathrm{UK})$. A calibration curve was determined using Trolox as an external standard with a range of concentration from 0 to $800 \mu$ moles. The absorbance was plotted against Trolox concentration, and the percentage of the absorbance reduction was used as a measure of the extract's antioxidant activity. The results were expressed as $\mu$ moles of Trolox per a kilogram of oil.

\section{Oxidative stability}

The oxidative stability was determined with the 743 Rancimat apparatus (Metrohm Co., Basel, Switzerland), an instrument for the automatic determination of the oils and fats oxidation stability. The level of stability was measured by the oxidative-induction time (OIT) using $3.5 \mathrm{~g}$ of oil. The temperature was set at $120^{\circ} \mathrm{C}$, while the purified air flow was regulated at a rate of $201 \mathrm{~h}^{-1}$. During the accelerated oxidation process, volatile acids were formed and measured conductimetrically. The induction period was determined as the time required at which the inflection point of the conductivity curve occurs (Halbault et al., 1997).

\section{CIE $L^{*} a^{*} b^{*}$ coordinates}

CieLab coordinates $\left(L^{*}, a^{*}\right.$ and $\left.b^{*}\right)$ were directly measured with a spectrophotometer colorimeter (Trintometer Lovibond PFX 195, Cambridge, UK). In this coordinate system, the $L^{*}$ value stands for lightness, thus representing the darkest black at $L^{*}=0$, and the brightest white at $L^{*}=100$. The $a^{*}$ value stands for the red/green axis and varies from -128 (greenness) to +128 (redness). The $b^{*}$ value, however, stands for the yellow/blue axis, which ranges between-128 (blueness) and +128 (yellowness).

\section{Data analysis}

All of the analyses were performed in triplicate and thus the results were expressed as mean values \pm standard 
666

deviations (SD). The data were subjected to statistical analysis using the Statsoft statistical software package (Statistica, 1998). The one-way analysis of variance (ANOVA), followed by the Tukey's range test, was implemented and the differences between individual means and each single used mean were deemed to be significant at $\mathrm{P}<0.05$.

\section{Results and Discussion}

The fatty acid composition of pumpkin seed oils is illustrated in Table 1. Of the saturated acids, two are dominant in the Cucurbita maxima cv. 'Béjaoui' seed oil: palmitic acid, which varies from $16.03 \%$ (in PSO1-Komet DD 85 G PSO) to $16.40 \%$ (in PSOH), and stearic acid, which ranges from $8.28 \%$ (in PSOH) to $8.57 \%$ (in PSOP and PSOCM). The concentrations of these two saturated fatty acids were higher than those observed by other authors in Cucurbita maxima and Cucurbita pepo seed oils (Younis et al., 2000; Nawirska-Olszańska et al., 2013; Seymen et al., 2016; Türkmen et al., 2017). Among the monounsaturated fatty acids (MUFA), oleic acid occurs in greatest amounts, from $28.19 \%$ (in PSO1-Komet DD 85 G PSO) to $30.56 \%$ (in PSOP). The concentration of oleic acid is higher than those reported earlier in Cucurbita maxima seed oils at the exception of the 'Ambar' (28.3\%) and 'Amazonka' (35.9\%) cultivar seed oils (Nawirska-Olszańska et al., 2013). Moreover, the concentration of oleic acid is lower than those cited by Seymen et al. (2016) and Türkmen et al. (2017) on Cucurbita pepo seed oils ranging between 31.57\% for genotype 2 and $49.72 \%$ for genotype 10 and between $31.65 \%$ for genotype 37 and $43.43 \%$ for genotype 106 , respectively. Of the polyunsaturated fatty acids (PUFA), linoleic acid was isolated with a content varying between 43.86\% (in PSOP) and 46.67\% (in PSO1-Komet DD 85 G PSO). The linoleic acid content is higher than those reported in Cucurbita pepo cold pressed seed oils at the exception of the K1 and the Austrian Gleisdorfer express samples (Rabrenović et al., 2014). Furthermore, lower contents of myristic and arachidonic acids were also detected. Concerning the contents of the major two fatty acids, statistically significant differences were found among the contents of linoleic acid, while the contents of oleic acid were not significantly different for PSOH and PSOCM.

Although the high linoleic acid content of the Cucurbita maxima cv. 'Béjaoui' seed oil makes it prone to oxidation, its fatty acid is nutritionally valuable and has many benefits for human health such as coronary heart disease and cancer prevention (Seymen et al., 2016). Likewise, the presence of a large proportion of oleic acid provides a high stability and makes the oil suitable for industrial applications.
Tocopherols are very important non-glyceride components of vegetable oils. Both the total content of these natural antioxidants and the presence of some of their isomers are contingent on some factors, namely the cultivar features, different oil types or extraction procedures, the utilized methods to determine tocopherol content, the weather conditions, and so on (Nederal Nakić et al., 2006).

Table 2 shows tocopherol composition and content in four analysed samples of cold pressed PSO, PSOH, PSOP, and PSOCM. Statistical examination has revealed significant differences in the tocopherol content among PSO samples. The obtained results have correspondingly demonstrated that the extraction technique significantly affects the content of the tocopherol under exploration. The $\gamma$-tocopherol was the only isomer detected with a content ranging from $84.15 \mathrm{mg} \mathrm{kg}^{-1}$ for PSOCM to 599.33 $\mathrm{mg} \mathrm{kg}^{-1}$ for the cold pressed PSO1 obtained by the Komet DD $85 \mathrm{G}$ press. The low content of $\gamma$-tocopherol in PSOCM could be attributed to the higher efficiency of chloroform/methanol in extracting the polar lipids, which is not totally miscible in the lower polarity hexane, during sample preparation and before column injection. Consistency of this hypothesis could be confirmed when comparing $\gamma$-tocopherol contents in PSOCM, PSOH $\left(239.60 \mathrm{mg} \mathrm{kg}^{-1}\right)$, and PSOP $\left(373.60 \mathrm{mg} \mathrm{kg}^{-1}\right)$. Higher amounts of the $\gamma$ - tocopherol in cold pressed PSO's (599.33 $\mathrm{mg} \mathrm{kg}^{-1}$ for PSO1, extracted with Komet DD 85 G press), could be attributed to the oil extraction process which excludes solvent use. Other authors confirmed the prevalence of $\beta+\gamma$ tocopherols ranging from $29.92 \mathrm{mg} / 100$ $\mathrm{g}$ to $53.6 \mathrm{mg} / 100 \mathrm{~g}$ in cold pressed Cucurbita pepo L. seed oils (Rabrenović et al., 2014). The $\gamma$-tocopherol is considered as the best antioxidant that prevents lipid oxidation by way of stabilizing hydroperoxyl and other free radicals (O'Brien, 2009). Because of the high $\gamma$-tocopherol content in PSOs, especially in cold pressed oil, they can be both used to prepare natural antioxidant formulations for commercial purposes.

Total Phenolic Contents (TPC) of pumpkin seed oils ranged from $23.27 \mathrm{mg} \mathrm{GAE} \mathrm{kg}^{-1}$ for $\mathrm{PSOH}$ to $54.41 \mathrm{mg}$ GAE kg ${ }^{-1}$ for PSOCM (Table 2). The content of TPC in Cucurbita maxima cv. 'Béjaoui' seed oil extracted by chloroform/methanol was higher than those of the PSOs extracted by pentane (PSOP), hexane (PSOH) and cold press extracted oil (PSO 1). These results indicated that the extraction of the pumpkin seed oil by apolar solvents only or by cold pressing were inappropriate for producing oil with enhanced TPC. Türkman et al. (2017) reported a total phenol content ranging from $0.25 \mathrm{mg} \mathrm{GAE} / 100 \mathrm{ml}$ to 0.35 $\mathrm{mg} \mathrm{GAE} / 100 \mathrm{ml}$ in 6 genotypes of Cucurbita pepo seeds. Other authors reported TPC values ranging from $56.94 \mathrm{mg}$ GAE/100g to $87.15 \mathrm{mg}$ GAE/100g for pumpkin

Table 1. Main Fatty Acid (\%) composition of Cucurbita maxima cv. 'Bejaoui' seed oils (a)

\begin{tabular}{|c|c|c|c|c|c|c|c|c|c|}
\hline Samples (b) & C14:0 & $\mathrm{C} 16: 0$ & C18:0 & C18:1 & C18:2 & C20:0 & SFA & MUFA & PUFA \\
\hline PSOH & $0.11 \pm 0.01 \mathrm{c}$ & $16.40 \pm 1.25 \mathrm{a}$ & $8.29 \pm 0.74 b$ & $29.47 \pm 1.58 b$ & $45.02 \pm 3.25 b$ & $0.60 \pm 0.05 a$ & $25.41 \pm 2.41 \mathrm{c}$ & $29.57 \pm 2.45 c$ & $45.01 \pm 3.41 \mathrm{~b}$ \\
\hline PSOP & $0.12 \pm 0.00 \mathrm{~b}$ & $16.17 \pm 2.32 b$ & $8.57 \pm 0.65 a$ & $30.56 \pm 2.87 \mathrm{a}$ & $43.86 \pm 5.24 d$ & $0.60 \pm 0.04 \mathrm{a}$ & $25.48 \pm 2.33 b$ & $30.67 \pm 2.78 \mathrm{a}$ & $43.86 \pm 2.36 \mathrm{~d}$ \\
\hline PSOCM & $0.14 \pm 0.00 \mathrm{a}$ & $16.19 \pm 1.89 \mathrm{~b}$ & $8.57 \pm 0.84 \mathrm{a}$ & $29.87 \pm 2.54 \mathrm{~b}$ & $44.48 \pm 4.25 c$ & $0.62 \pm 0.05 a$ & $25.53 \pm 2.58 \mathrm{a}$ & $30.00 \pm 2.94 b$ & $44.48 \pm 4.25 c$ \\
\hline PSO 1 & $0.11 \pm 0.00 \mathrm{c}$ & $16.03 \pm 2.36 \mathrm{c}$ & $8.28 \pm 0.81 \mathrm{~b}$ & $28.19 \pm 1.98 \mathrm{c}$ & $46.67 \pm 4.12 \mathrm{a}$ & $0.60 \pm 0.06 \mathrm{a}$ & $25.03 \pm 2.13 \mathrm{~d}$ & $28.29 \pm 2.14 \mathrm{~d}$ & $46.67 \pm 4.59 a$ \\
\hline
\end{tabular}

(a) SFA: Saturated Fatty Acids; MUFA: Monounsaturated Fatty Acids; PUFA: Polyunsaturated Fatty Acids; tr.: trace amounts (less than 0.2\%).
Values are means \pm SD of three determinations. Mean values with different letters in the same column are significantly different.

(b) PSOH (Pumpkin Seed Oil Hexane extraction); PSOP (Pumpkin Seed Oil Pentane extraction); PSOCM (Pumpkin Seed Oil Chloroform/Methanol extraction); and PSO1 (Pumpkin Seed Oil obtained by Komet DD 85 G Press). 
(Cucurbita pepo) seed methanolic extracts, which were higher than those reported in our study (Seymen et al., 2016). Different values of TPC for the pumpkin seed oil have been documented by other researchers, probably because of the difference in the extraction methods, environmental conditions of plant or harvesting time.

Results of quantitative analysis of phenolic compounds in extracts from pumpkin Cucurbita maxima cv. 'Béjaoui' seed oils are summarized in Table 2. Pumpkin seed oils are not rich in phenolics. Only p-hydroxybenzoic and phydroxybenzaldehyde acids were identified. An unidentified peak at a retention time of $13.18 \mathrm{~min}$ and a $\mathrm{m} / \mathrm{z}(\mathrm{M}-\mathrm{H})^{-}$of 429 was observed in all extracts. The $\mathrm{m} / \mathrm{z} 429$ ion was subjected to $\mathrm{MS}^{\mathrm{n}}$ analysis to produce signals at $\mathrm{m} / \mathrm{z} 277$ and $\mathrm{m} / \mathrm{z} 266$, respectively (data not shown). The peak is believed to correspond to two typical phenolic acid derivatives of the pumpkin seed. It is worth noting that Cucurbita maxima seed oil extracted by chloroform/methanol showed the highest amounts of phenolic acids. Phenolic acid concentrations were of $23.78 \mathrm{mg} \mathrm{kg}^{-1}, 138.46 \mathrm{mg} \mathrm{kg}^{-1}$, and $58.75 \mathrm{mg} \mathrm{kg}^{-1}$ for p- hydroxybenzoic acid, phydroxybenzaldehyde acid, and the non-identified peak, respectively. This result could be explained by the higher polarity of the chloroform/methanol solvent when compared to hexane and pentane, which enhances polar phenolic acid extraction.

Not only does the presence of pigments determine the product colour, but it also plays an important role in the oxidative activity because of their antioxidant nature in the dark and pro-oxidant activity in the light (Oueslati $e t$ al., 2009). Carotenoid contents in pumpkin seed oils are best illustrated in Table 3. Statistical analysis has revealed significant differences in carotenoid content between different PSOs. The obtained results have well demonstrated that the oil extraction method significantly affect the content of carotenoids being analyzed. PSOP demonstrated the lowest carotenoids content $(5.96 \mathrm{mg}$ $\mathrm{kg}^{-1}$ ), however the highest content was observed in PSOH $\left(27.48 \mathrm{mg} \mathrm{kg}^{-1}\right)$.

The result of the Rancimat test is shown in Table 3. The stability of PSOs expressed as the oxidation induction time varied between $1.38 \mathrm{~h}$ and $2.79 \mathrm{~h}$ for the pumpkin seed oil that is extracted by chloroform/methanol and pentane, respectively. Statistical analysis demonstrated significant differences between PSO samples and proved that the extraction technique greatly affects their oxidation induction time as well as the $\gamma$-tocopherol content. When compared to the solvent-extracted, the cold-pressed pumpkin seed oil exhibited higher oxidation induction time
(3.84 h for PSO1 extracted with Komet DD 85 G press). The obtained results are lower than those found in purslane seed oils (Delfan-Hosseini et al., 2017). The values of the induction period for the solvent-extracted, cold press extracted and microwave pretreatment-cold press extracted oils were $5.12,4.64$ and $9.67 \mathrm{~h}$, respectively. The high oil stability was attributed to the high content of total polyphenol content and to a high antioxidant activity.

The antioxidant activities of PSOs were determined using the DPPH as a stable radical and Trolox as an external standard. The analysis of the scavenging activity on DPPH radicals provides adequate information to determine the antiradical activity of PSOs. The methanol-extracted PSO's radical scavenging activities, expressed as $\mu$ moles Trolox $\mathrm{kg}^{-1}$, varied between $100 \mu$ moles Trolox kg ${ }^{-1}$ for PSOP and 250 $\mu$ moles Trolox kg-1 for PSOCM (Table 3). The PSOs' antioxidant activity is much higher than those reported on Cucurbita maxima and Cucurbita pepo seed cultivars (Nawirska-Olszańska et al., 2013). In fact, the antioxidant activity, expressed as Trolox Equivalent Antioxidant Capacity (TEAC), ranged from 0.73 TEAC to 1.51 TEAC for the Cucurbita maxima cultivars, and from 0.664 TEAC to 1.34 TEAC for the Cucurbita pepo cultivars, respectively. Other researchers reported an antioxidant activity ranging between $5.44 \%$ and $17.75 \%$ and between $0.19 \%$ and $11.75 \%$ in Cucubita pepo seed genotypes (Seymen et al., 2016; Türkmen et al., 2017).

It is worth mentioning now that there is a linear correlation between the total phenolic content and the scavenging activity against DPPH for the PSO extracted by solvents and the cold-pressed PSO obtained by the Komet DD $85 \mathrm{G}$ press. The chloroform/methanol extracted PSO, rich in total phenolics, was a more effective scavenger of DPPH radicals than poor phenolic pumpkin seed oils extracted by hexane and pentane. Consistency can be seen between our results and those obtained by other authors who analyzed the total phenolic content and scavenging activity against DPPH in pumpkin seed extracts obtained with solvents of reduced polarity (Xanthopoulou et al., 2009). However, the inhibition of DPPH radical scavenging by pumpkin seed oils is not strictly proportional to the concentration of total phenolic compounds. This might be referred to the different quality of phenolics they contain, to the different antioxidant activity they have, and correspondingly to the different content of other components (carbohydrates, phospholipids, and fatty acids) that may greatly contribute to the antioxidant activity (Xanthopoulou et al., 2009).

Table 2. Tocopherol composition, Total Phenolic Content (TPC) and phenolic compounds of Cucurbita maxima cv. 'Bejaoui' seed oils (a)

\begin{tabular}{cccccc}
\hline $\begin{array}{c}\text { Samples } \\
\text { (b) }\end{array}$ & $\begin{array}{c}\gamma \text {-Tocopherol } \\
(\mathrm{mg} \mathrm{kg}-1)\end{array}$ & $\begin{array}{c}\text { TPC } \\
\left(\mathrm{mg} \mathrm{GAE} \mathrm{kg}^{-1}\right)\end{array}$ & $\begin{array}{c}\text { p-hydroxybenzoic } \\
\left(\mathrm{mg} \mathrm{kg}^{-1}\right)\end{array}$ & $\begin{array}{c}\text { p-hydroxybenzaldehyde } \\
(\mathrm{mg} \mathrm{kg}-1)\end{array}$ & $\begin{array}{c}\mathrm{ni} \\
\left(\mathrm{mg} \mathrm{kg}^{-1}\right)\end{array}$ \\
\hline PSOH & $239.60 \pm 22.15 \mathrm{c}$ & $23.32 \pm 2.85 \mathrm{c}$ & $0.98 \pm 0.08 \mathrm{~b}$ & $0.85 \pm 0.07 \mathrm{c}$ & $0.60 \pm 0.05 \mathrm{~d}$ \\
PSOP & $373.60 \pm 32.54 \mathrm{~b}$ & $23.27 \pm 2.14 \mathrm{c}$ & $0.19 \pm 0.01 \mathrm{c}$ & $0.59 \pm 0.06 \mathrm{~d}$ & $2.45 \pm 0.02 \mathrm{c}$ \\
PSOCM & $84.15 \pm 7.41 \mathrm{~d}$ & $54.41 \pm 4.12 \mathrm{a}$ & $23.78 \pm 2.54 \mathrm{a}$ & $138.46 \pm 12.59 \mathrm{a}$ & $58.75 \pm 5.21 \mathrm{a}$ \\
PSO 1 & $599.33 \pm 54.81 \mathrm{a}$ & $39.77 \pm 2.53 \mathrm{~b}$ & $0.11 \pm 0.01 \mathrm{~d}$ & $0.97 \pm 0.08 \mathrm{~b}$ & $4.81 \pm 0.03 \mathrm{~b}$ \\
\hline
\end{tabular}

(a)Values are means \pm SD of three determinations. Mean values with different letters in the same column are significantly different. (b) PSOH (Pumpkin Seed Oil Hexane extraction); PSOP (Pumpkin Seed Oil Pentane extraction); PSOCM (Pumpkin Seed Oil chloroform/methanol extraction); and PSO1(Pumpkin Seed Oil obtained by Komet DD 85 G Press). Phenolic compounds expressed as p-hydroxybenzoic acid. ni: not identified phenolic compound. 
668

Table 3. Anti-oxidant activity, oxidative stability, carotenoid content, and Cielab coordinates $\left(L^{*}, a^{*}, b^{*}\right)$ of Cucurbita maxima cv. 'Bejaoui' seed oils (a)

\begin{tabular}{ccccccc}
\hline $\begin{array}{c}\text { Samples } \\
(\mathrm{b})\end{array}$ & $\begin{array}{c}\text { DPPH } \\
\left.(\mu \text { moles Trolox kg })^{-1}\right)\end{array}$ & $\begin{array}{c}\text { Oxidative stability } \\
(\mathrm{h})\end{array}$ & $\begin{array}{c}\text { Carotenoids } \\
\left(\mathrm{mg} \mathrm{kg}^{-1}\right)\end{array}$ & $\mathrm{L}^{*}$ & $\mathrm{a}^{*}$ & $\mathrm{~b}^{*}$ \\
\hline PSOH & $110 \pm 10 \mathrm{c}$ & $2.51 \pm 0.20 \mathrm{c}$ & $27.48 \pm 1.41 \mathrm{a}$ & $39.02 \pm 3.22 \mathrm{c}$ & $25.95 \pm 2.51 \mathrm{a}$ & $63.10 \pm 5.93 \mathrm{a}$ \\
PSOP & $100 \pm 10 \mathrm{~cd}$ & $2.79 \pm 0.31 \mathrm{~b}$ & $5.96 \pm 1.24 \mathrm{~d}$ & $73.14 \pm 6.28 \mathrm{a}$ & $-9.03 \pm 0.85 \mathrm{c}$ & $57.92 \pm 4.52 \mathrm{c}$ \\
PSOCM & $250 \pm 20 \mathrm{a}$ & $1.38 \pm 0.10 \mathrm{~d}$ & $11.85 \pm 1.06 \mathrm{c}$ & nd & nd & nd \\
PSO 1 & $150 \pm 10 \mathrm{~b}$ & $3.84 \pm 0.40 \mathrm{a}$ & $12.03 \pm 1.50 \mathrm{~b}$ & $55.10 \pm 4.58 \mathrm{~b}$ & $10.48 \pm 1.21 \mathrm{~b}$ & $58.88 \pm 6.15 \mathrm{~b}$ \\
\hline
\end{tabular}

(a) Values are means \pm SD of three determinations. Mean values with different letters in the same column are significantly different.

(b) PSOH (Pumpkin Seed Oil Hexane extraction); PSOP (Pumpkin Seed Oil Pentane extraction); PSCM (Pumpkin Seed Oil chloroform/methanol extraction); and PSO1 (Pumpkin Seed Oil obtained by Komet DD 85 G Press).

nd: not determined ( $\mathrm{a}^{*}$ and $\mathrm{b}^{*}$ were not determined due to the darkness of the sample which indicates a saturated signal).

Cielab coordinates values $\left(L^{*}, a^{*}, b^{*}\right)$ of pumpkin seed oils are illustrated in Table 3. Pumpkin seed oil extracted by pentane showed the highest $L^{*}$ (73.14). This means that this oil is lighter than the other PSOs. Higher values of $a^{*}$ and $b^{*}$ were apparent in the pumpkin seed oil extracted by hexane and which account for the presence of yellow and red pigments such as carotenoids. Relevance can be detected in $a^{*}$ and $b^{*}$ values and in carotenoid content in PSOH $\left(27.48 \mathrm{mg} \mathrm{kg}^{-1}\right)$. When compared to other vegetable oils, Cielab $\left(L^{*}, a^{*}, b^{*}\right)$ values of PSOs-at the exception of PSOP's $a^{*}$ value-are higher than those of palm, soybean, sunflower, olive, corn, and pumpkin with a range of 25 to 69.5, 3.8 to 10, and 9.2 to 38, respectively (Hsu and $\mathrm{Yu}$, 2002; Nyam et al., 2009).

\section{Conclusions}

This study has revealed, to a certain extent, that the pumpkin seed oil features are markedly influenced by the extraction techniques. The cold press extraction method seems to be a viable alternative to solvent use and considerably meets the growing consumer demand for many valuable natural nutrients that appear to have a number of benefits to human health. The high content of these bioactive compounds such as phenolics, tocopherols, and carotenoids both highlights their nutritional and medicinal values and provides a high protection against oxidative stress. In the long run, a good shelf life and other beneficial characteristics make the cold-pressed pumpkin seed oil not only an ideal contaminant-free natural product, but also an ideal ingredient for pharmaceutical and cosmetic products. Additional research in the quality of the coldpressed pumpkin seed oil might pave the way for a potential wide application in the industrial field.

\section{Acknowledgements}

This research received no specific grant from any funding agency in the public, commercial, or not-for-profit sectors. The authors would like to kindly thank Mr. Anis Tounsi, Higher Institute of Technological Studies of Zaghouan, for his valuable effort to proofread this paper.

\section{References}

AOCS (1989). Official methods and recommended practices of the American Oil Chemists' Society, 4th Ed. Firestone D. AOCS,

\section{Champaign, USA.}

Brand-Williams W, Cuvelier ME, Berset C (1995). Use of a free radical method to evaluate antioxidant activity. Lebensmittel - Wissenschaft und Technologie 28(1):25-30.

Castillo-Muñoz N, Gómez-Alonso S, García-Romero E, Victoria Gómez M, Velders AH, Hermosín-Gutiérrez I (2009). Flavonol 3-O-gycosides series of Vitis viniferacr. Petit Verdot red wine grapes. Journal of Agricultural and Food Chemistry 57(1):209-219.

Delfan-Hosseini S, Nayebzadeh K, Mirmoghtadaie L, Kavosi M, Marzieh Hosseini S (2017). Effect of extraction process on composition, oxidative stability and rheological properties of purslane seed oil. Food Chemistry 222:61-66.

European Economic Community (1991). Characteristics of olive and olive pomace oils and their analytical methods, Regulation EEC/2568/1991. Journal of the European Community L248:1-82.

Gutfinger T (1981). Polyphenols in Olive Oil. Journal of the American Oil Chemists' Society 58(11):966-968.

Halbault L, Barbe C, Aroztegui M, De La Torre C (1997). Oxidative stability of semi solid excipient mixtures with corn oil and its implication in the degradation of vitamin A. International Journal of Pharmaceutics 147:31-41.

Hsu SY, Yu SH (2002). Comparisons on 11 plant oil fat substitutes for lowfat kung-wans.Journal of Food Engineering 51:215-220.

Jiao J, Li ZG, Gai QY, Li XJ, Wei FY, Fu YJ, Ma W (2014). Microwaveassisted aqueous enzymatic extraction of oil from pumpkin seeds and evaluation of its physicochemical properties, fatty acid compositions and antioxidant activities. Food Chemistry 147:17-24.

Martinez ML, Penci MC, Ixtaina V, Ribotta PD, Maestri D (2013). Effect of natural and synthetic antioxidants on the oxidative stability of walnut oil under different storage conditions. Food Science and Technology 51:4450.

Mínguez-Mosquera MI, Rejano L, Gandul B, Sanchez AH, Garrido J (1991). Color-pigment correlation in virgin olive oil. Journal of the American Oil Chemists' Society 68:332-336.

Mitra P, Ramaswamy HS, Chang KS (2009). Pumpkin (Cucurbita maxima) seed oil extraction using supercritical carbon dioxide and physicochemical properties of the oil. Journal of Food Engineering 95:208-213.

Murković M, Piironen V, Lampi, AM, Kraushofer T, Sontag G (2004). Changes in chemical composition of pumpkin seeds during roasting process for production of pumpkin seed oil (Part 1: non-volatile compounds). Food Chemistry 84:359-365. 
Nawirska-Olszańska A, Kita A, Biesiada A, Sokół-Łętowska A, Kucharska AZ (2013). Characteristics of antioxidant activity and composition of pumpkin seed oils in 12 cultivars. Food Chemistry 139:155-161.

Nederal Nakić S, Petrović M, Vincek D, Pukec D, Škevin D, Kraljić K, Obranović M (2014). Variance of quality parameters and fatty acid composition in pumpkin seed oil during three crop seasons. Industrial Crops and Products 60:15-21.

Nederal Nakić S, Rade D, Škevin D, Štrucelj D, Mokrovčak Ž, Bartolić M (2006). Chemical characteristics of oils from naked and husk seeds of Cucurbita pepo L. European Journal of Lipid Science and Technology 108:936-943.

Nishimura M, Ohkawara T, Sato H, Takeda H, Nishihira J (2014). Pumpkin seed oil extracted from Cucurbita maxima improves urinary disorder in Human overactive. Journal of Traditional and Complementary Medicine 4:72-74.

Nyam KL, Tan CP, Lai OM, Long K, Che ManYB (2009). Physicochemical properties and bioactive compounds of selected seed oils. Food Science and Technology 42:1396-1403.

O'Brien RD (2009). Fats and oils: Formulations and processing for applications. Boca Raton.

Oueslati I, Anniva C, Daoued D, Tsimidou MZ, Zarrouk M (2009). Virgin olive oil (VOO) production in Tunisia: the commercial potential of the major olive varieties from the arid Tataouine zone. Food Chemistry 112:733-741.

QiQ(2012).Study on extraction of pumpkin seed oil by aqueous enzymatic method. Journal of Anhui Agriculture Science 40:7410-7413.

Rabrenović BB, Dimić EB, Novaković MM, Tešević VV, BasićZN (2014). The most important bioactive components of cold pressed oil from different pumpkin (Cucurbita pepo L.) seeds. Food Science and Technology 55(2):521-527.
Rezig L, Chouaibi M, Msaada, K, Hamdi S (2012). Chemical composition and profile characterisation of pumpkin (Cucurbita maxima) seed oil. Industrial Crops and Products 37:82-87.

Salgin U, Korkmaz H (2011). A green separation process for recovery of healthy oil from pumpkin seed. The Journal of Supercritical Fluids 58:239-248.

Seymen M, Uslu N, Türkmen Ö, Al Juhaimi F, Özcan MM (2016). Chemical compositions and mineral contents of some hull-less pumpkin seed and oils. Journal of the American Oil Chemists' Society 93:1095-1099.

STATISTICA (1998). Statsoft, Inc, Tulsa, OK, USA.

Stevenson DG, Eller FJ, Wang L, Jane JL, Wang T, Inglett GE (2007). Oil and tocopherol content and composition of pumpkin seed oil in 12 cultivars.Journal of Agricultural and Food Chemistry 55:4005-4013.

Türkmen Ö, Özcan MM, Seymen M, Paksoy M, Uslu N, Fidan S (2017). Physico-chemical properties and fatty acid compositions of some edible pumpkin seed genotypes and oils. Journal of Agroalimentary Processes and Technologies 23(4):229-235.

Vázquez-Roncero A, Janer Del Valle C, Janer Del Valle ML (1973). Determinación de los polifenoles totales del aceite de oliva. Grasas Aceites 24:350-357.

Xanthopoulou MN, Nomikos T, Fragopoulou E, Antonopoulou S (2009). Antioxidant and lipoxygenase inhibitory activities of pumpkin seed extracts. Food Research International 42:641-646.

Younis YMH, Ghirmay S, Al-Shihry SS (2000). African Cucurbita pepo L.: properties of seed and variability in fatty acid composition of seed oil. Phytochemistry 54:71-75. 